\title{
O movimento indígena e a educação escolar
}

\author{
El movimiento indígena y la educación escolar
}

The indigenous movement and school education

\author{
Clara Balladares Machado ${ }^{1}$ \\ Adriana Duarte Leon ${ }^{2}$
}

\begin{abstract}
Resumo
Neste artigo abordamos as políticas públicas que orientam o ensino da história e da cultura indígena na escola pública. Busca-se compreender a influência que o Movimento Indígena exerce para que a sua história e a sua cultura possam se tornar protagonistas na escola. Para tanto foi feito um levantamento bibliográfico exploratório sobre o tema, tendo como referência as políticas que normatizam o ensino da história e cultura indígena, tais como: Constituição Federal de 1988, Lei de Diretrizes e Bases da Educação 9.394/96, Parâmetros Curriculares Nacionais, Lei 11.645/08 e programas do governo que investem nas bibliotecas escolares e acervos literários, que buscam proporcionar ao professor acesso a livros que tratam do ensino da história e da cultura afrobrasileira e indígena. A partir desse estudo, pode-se perceber que o Movimento Indígena tem crescido e influenciado na criação de normativas que tornam a temática indígena, de certa forma, presente nos currículos escolares e, aos poucos, na realidade das escolas brasileiras.
\end{abstract}

Palavras-Chave: ensino escolar indígena, políticas públicas, história e cultura indígena.

\section{Resumen}

En este artículo abordamos las políticas públicas que orientan la enseñanza de la historia y de la cultura indígena en la escuela pública. Se ha buscado entender la influencia que el Movimiento Indígena ejerce para que su historia y su cultura puedan lograr el protagonismo en el medio escolar. Para eso, fue hecho una búsqueda bibliográfica a respecto del tema, teniendo por referencia las políticas que dan las normas a la enseñanza de la historia y cultura indígena, por ejemplo: Constitución Federal de 1988, Ley de Directrices y Bases de la Educación 9.394/96, Parámetros Curriculares Nacionales, Ley 11.645/08 y programas del gobierno que invisten en las bibliotecas escolares y acervos literarios, que buscan propiciar a los profesores acceso a libros que tratan de la enseñanza de la historia y de la cultura afrobrasileña y indígena. A partir de esa investigación fue posible percibir que el Movimiento Indígena ha crecido y ha influenciado en el desarrollo de nuevas normas que hacen con que la temática indígena, de alguna manera, aparezca presente en los currículos escolares y, gradualmente, real en las escuelas brasileñas.

Palabras claves: enseñanza escolar indígena, políticas públicas, história e historia y cultura indígena.

\begin{abstract}
This paper discusses the public policies that guide the teaching of history and indigenous culture in the public school. It seeks to understand how the Indigenous Movement exerts influence to its history and its culture becoming protagonists in the school. With this aim, an exploratory bibliographical research was performed using as reference the policies that regulate the teaching of indigenous history and culture, such as: Federal Constitution of 1988, Law of Guidelines and Bases of Education - Law 9.394/96, National Curricular Parameters, Law 11.645/08 and government programs that invest in school libraries and literary collections, which intends to provide the teacher with access to books about the teaching of Afro-Brazilian and Indigenous history and culture. Through this research, it can be concluded that the Indigenous Movement has grown and has
\end{abstract}

\footnotetext{
${ }^{1}$ Mestranda Profissional em Educação e Tecnologias.; Instituto Federal de Educação, Ciência e Tecnologia SulRio-Grandense, IFSUL, RS, Brasil; claraballadares@gmail.com

${ }^{2}$ Doutora em Educação; Universidade Federal de Minas Gerais, UFMG, Brasil, adriana.adrileon@ gmail.com
} 
influenced the creation of norms that include, the indigenous theme, in some way, in the school curriculum and, gradually, in the reality of the Brazilian schools.

Keywords: Indigenous School Subject; Public Policies; Indigenous History; Indigenous Culture.

\title{
1. Introdução
}

Este trabalho é um recorte da pesquisa de mestrado em educação que está em andamento sobre o ensino da temática indígena na escola, mais especificamente no ensino fundamental. Nele buscamos compreender como o Movimento Indígena, surgido na década de 1970 no Brasil tem influenciado as leis que orientam o ensino da temática indígena na escola, principalmente no que diz respeito à valorização das diferentes culturas e histórias desses povos.

Sabemos que a nossa sociedade encontra-se engendrada numa pluralidade ${ }^{3}$, que não existe o certo e o errado quando se trata de cultura. Por isso, todas devem ser vivenciadas e respeitadas.

Desde a divulgação dos Parâmetros Curriculares Nacionais (BRASIL, 1997), tem-se falado muito em pluralidade cultural, e percebido que, por muito tempo, as culturas pertencentes aos grupos minoritários foram suprimidas e/ou desvalorizadas na escola por meio de um pensamento baseado na cultura eurocêntrica. Quando a ideia de pluralidade passa a fazer parte do pensamento escolar, surge outra questão: a escola deve trabalhar a diversidade cultural? Como? Com quais objetivos? O próprio PCN (BRASIL, 1997) apresenta que:

\begin{abstract}
É importante, ao tratar este assunto, fazer-se a distinção entre diversidade cultural, a que o tema se refere, e desigualdade social. As culturas são produzidas pelos grupos sociais ao longo das suas histórias, na construção de suas formas de subsistência, na organização da vida social e política, nas suas relações com o meio e com outros grupos, na produção de conhecimentos, etc. A diferença entre culturas é fruto da singularidade desses processos em cada grupo social. A desigualdade social é uma diferença de outra natureza: é produzida na relação de dominação e exploração socioeconômica e política. Quando se propõe o conhecimento e a valorização da pluralidade cultural brasileira não se pretende deixar de lado essa questão. Ao contrário, principalmente no que se refere à discriminação, é impossível compreendê-la sem recorrer ao contexto social em que acontece e à estrutura autoritária que marca a sociedade. As produções culturais não ocorrem "fora" de relações de poder: são constituídas e marcadas por ele, envolvendo um permanente processo de reformulação e resistência (BRASIL, 1997).
\end{abstract}

A diversidade cultural precisa ser vivida, compartilhada e valorizada, pois é a partir da ideia de que todas as culturas são importantes para a formação da identidade brasileira que o

\footnotetext{
${ }^{3} \mathrm{O}$ termo pluralidade está relacionado à ideia de multiculturalidade da nação, ou seja, o Brasil, devido a sua colonização tão diversificada, é formado por diversas culturas o que o torna plural nesta categoria.
} 
preconceito cultural será superado. Ao encontro de tal pensamento, Souza \& Fleuri (2003) afirmam que:

A educação cultural, não sendo uma disciplina, coloca-se como outra modalidade de pensar, propor, produzir e dialogar com as relações de aprendizagem, contrapondose àquela tradicionalmente polarizada, homogeneizante e universalizante (SOUZA; FLEURI, 2003, p.71).

Desde 2008 a lei 11.645 determina o ensino da história e cultura afro-brasileira e indígena em todos os componentes curriculares. Essa lei faz com que as questões indígenas e afro-brasileiras deixem de fazer parte apenas da história de formação do nosso país e passem a fazer parte do nosso presente. Índios e negros sempre foram vistos, na nossa produção historiográfica, como seres do passado, que fizeram parte dos primeiros anos de formação do nosso país. Após a consolidação do Brasil como uma nação, parece que esses grupos deixam de existir e que o Brasil passa a ser construído apenas pela cultura branca de descendência européia. Essa é a grande mudança que se espera a partir dessa lei, que cada vez mais as diferenças étnico-raciais sejam vistas e valorizadas na sociedade, a escola é o principal meio de valorização dessas culturas.

\section{O Movimento Indígena e sua trajetória}

Para tratarmos sobre o ensino da temática indígena na escola, acreditamos ser importante uma referência ao Movimento Indígena. Com a organização de grupos indígenas, em diversas regiões do país, foram conquistados e garantidos diversos direitos, dentre eles o reconhecimento de uma educação escolar indígena que já é implantada em algumas tribos, favoreceu também o acesso ao ensino superior por muitos indígenas, incluindo aí os programas de cotas, inclusive com a criação de cursos específicos para essa população. Como fundamentação teórica desse texto, utilizamos como referência ao trabalho de Daniel Munduruku (2012), livro publicado com base em sua tese de doutorado intitulada "O caráter educativo do movimento indígena brasileira (1970-1990)". Este é um trabalho rico em detalhes sobre o movimento e o longo caminho percorrido por ele. E também procuramos suporte em artigos publicados em revistas disponíveis no Scielo e em dissertações de mestrados disponíveis no banco de teses e dissertações da CAPES.

Para falar sobre o movimento indígena é necessário nos remetermos ao processo colonizador do Brasil, o qual submeteu a figura dos povos originários de nossa terra, chamados de forma generalizada de índios, a uma visão romantizada e de submissão. Com um olhar eurocêntrico, a participação dos indígenas na formação da colônia e posteriormente da 
nação brasileira ficou restrita a exploração dos bens naturais da terra para enriquecer a coroa portuguesa e como forma de garantir a posse das terras aqui encontradas. Por isso, sua imagem foi marcada por seres que viviam nus, que, apesar de suas inúmeras crenças, não tinham uma religião nem um rei, portanto precisavam ser catequizados e subordinados pela coroa portuguesa. Essa ideia de povos inferiores ocasionou o extermínio de muitos povos indígenas na primeira fase da colonização portuguesa no Brasil. De acordo com Munduruku (2012, p. 27):

O primeiro grande modelo colocado em prática desde o momento da chegada dos europeus é conhecido como paradigma exterminacionista, e seu objetivo era a destruição em massa dos povos indígenas. Tal política era assim desfechada porque era senso comum à época dizer que os nativos que aqui habitavam não tinham alma e, como tal, qualquer carnificina cometida era devidamente perdoada por Deus através de sua igreja. (MUNDURUKU, 2012, p. 27)

Ao longo da história do Brasil (colônia, império, república), a figura do indígena foi sendo adaptada e recontada de modo que justificasse sempre a sua situação de submissão. $\mathrm{O}$ Estado brasileiro constrói no campo discursivo uma função assistencialista em relação aos povos indígenas e em diversos momentos afirma-se como responsável pelo cuidado dos mesmos.

O segundo modelo de política indigenista no Brasil provem de um paradigma integracionista, momento em que o governo republicano assume a política brasileira. Voltouse então a uma legislação tutelar, pois era necessário proteger esses povos com uma cultura inferior à européia e fadados ao desaparecimento. Citando Munduruku (2012):

Assim, quando o governo republicano tomou posse do Brasil, foi necessário dar uma nova direção a uma política indigenista baseada numa legislação tutelar, o que levou a uma solução estatal que culminou na criação do Serviço de Proteção ao Índio (SPI), em 1910. (MUNDURUKU, 2012, P. 31)

Em linhas gerais o SPI foi um marco nas políticas indigenistas, pois foi o primeiro a tratar como lei a questão indígena no Brasil. Tinha como fundamentação "o respeito aos povos indígenas, aos seus direitos de identidade e diversidade cultural. Com relação a essas últimas, acreditava-se que poderiam com o passar do tempo ser mudadas para inseri-los na comunhão nacional” (MUNDURUKU, 2012, p.33).

O SPI acabou por fracassar, sendo desestruturado com o passar do tempo devido à falta de verbas, falta de pessoas qualificadas e envolvidas com a causa indígena, descompromisso político e fracasso administrativo. O golpe militar, iniciado no ano de 1964 também proporcionou uma mudança de postura na política indigenista, o que levou a criação da Fundação Nacional do Índio (Funai) no ano de 1967. 
A Funai, inicialmente, teve todas as condições necessárias para uma boa atuação. Porém, manteve-se sob direção militar, o que favoreceu a ocupação de cargos por pessoas não envolvidas com a questão indígena e omissas em relação à posse de terras dos territórios indígenas, cujo programa de demarcação de terras da então política militar favoreceu a ocupação ilegal de terras.

A ideia de tutoria ou "paradigma integracionista" denominação utilizada por Munduruku (2012) estendeu-se até meados da década de 1970, período em que o chamado Movimento Indígena começou a ganhar força no Brasil, tendo em vista a demarcação de terras em relação às políticas do período militar.

O objetivo do movimento indígena é a conservação e delimitação de áreas indígenas. Esse conceito vai além da definição literal da posse de terra, ele engloba o direito à educação, saúde, respeito e reconhecimento à cultura e demarcação de terras.

A primeira conquista do movimento indígena, e que proporcionou a sua consolidação, foi na Constituição Federal de 1988 em que os direitos indígenas foram incluídos em seus artigos 231 e 232:

Art. 231. São reconhecidos aos índios sua organização social, costumes, línguas, crenças e tradições, e os direitos originários sobre as terras que tradicionalmente ocupam, competindo à União demarcá-las, proteger e fazer respeitar todos os seus bens.

$\$ \mathbf{1}^{\mathbf{0}}$ São terras tradicionalmente ocupadas pelos índios as por eles habitadas em caráter permanente, as utilizadas para suas atividades produtivas, as imprescindíveis à preservação dos recursos ambientais necessários a seu bem-estar e as necessárias a sua reprodução física e cultural, segundo seus usos, costumes e tradições.

$\$ \mathbf{2}^{\mathbf{0}}$ As terras tradicionalmente ocupadas pelos índios destinam-se a sua posse permanente, cabendo-lhes o usufruto exclusivo das riquezas do solo, dos rios e dos lagos nelas existentes.

$\S 3^{\circ} \mathrm{O}$ aproveitamento dos recursos hídricos, incluídos os potenciais energéticos, a pesquisa e a lavra das riquezas minerais em terras indígenas só podem ser efetivados com autorização do Congresso Nacional, ouvidas as comunidades afetadas, ficando-lhes assegurada participação nos resultados da lavra, na forma da lei.

$\S 4^{\circ}$ As terras de que trata este artigo são inalienáveis e indisponíveis, e os direitos sobre elas, imprescritíveis.

§ 5 É vedada a remoção dos grupos indígenas de suas terras, salvo, ad referendum do Congresso Nacional, em caso de catástrofe ou epidemia que ponha em risco sua população, ou no interesse da soberania do País, após deliberação do Congresso Nacional, garantido, em qualquer hipótese, o retorno imediato logo que cesse o risco.

\$ $6^{\circ}$ São nulos e extintos, não produzindo efeitos jurídicos, os atos que tenham por objeto a ocupação, o domínio e a posse das terras a que se refere este artigo, ou a exploração das riquezas naturais do solo, dos rios e dos lagos nelas existentes, ressalvado relevante interesse público da União, segundo o que dispuser lei complementar, não gerando a nulidade e a extinção direito a indenização ou a ações contra a União, salvo, na forma da lei, quanto às benfeitorias derivadas da ocupação de boa-fé.

$\S 7^{\mathbf{0}}$ Não se aplica às terras indígenas o disposto no art. $174, \S \S 3^{\circ}$ e $4^{\circ}$. 
Art. 232. Os índios, suas comunidades e organizações são partes legítimas para ingressar em juízo em defesa de seus direitos e interesses, intervindo o Ministério Público em todos os atos do processo. (BRASIL, 1988).

Esses artigos da CF/88 estabelecem, então, o direito a um ensino indígena, ou seja, o reconhecimento de que existe uma cultura indígena diversificada no Brasil e de que ela precisa manter-se viva, em oposição à ideia anterior, em que o indígena deveria absorver a cultura européia predominante na nação brasileira. De acordo com LIMA e CARIE (2013):

Com esse reconhecimento legal, os povos indígenas conquistaram a inclusão de uma educação indígena diferenciada no texto da lei e o estabelecimento de escolas indígenas em seus territórios, algo que já era praticado por muitos povos indígenas. Desde então, muitas iniciativas no âmbito da educação e cultura indígena têm ocorrido, com destaque para a literatura indígena, escrita em português e em línguas indígenas, e a implementação de cursos de formação de professores indígenas em nível médio e superior. (LIMA e CARIE, 2013, P. 54)

Ainda sobre as conquista da CF-88, Munduruku (2012) afirma que essa nova política indigenista torna-se "[..]defensora do multiculturalismo e do pluralismo jurídico, ao reconhecer a organização social, costumes, línguas, crenças e tradições como direitos subjetivos dos povos indígenas [..]” ( MUNDURUKU, 2012, P.37).

A Carta magna de 1988 acabou por influenciar a Lei de Diretrizes e Bases da Educação Nacional (LDBEN) Lei n. 9.394, de 1996 - voltando a falar aqui na educação escolar indígena, tema desse trabalho - em seu artigo 32, em que assegura às comunidades indígenas a utilização de suas línguas maternas e processos próprios de aprendizagem, facilitando a recuperação de suas memórias históricas, a reafirmação de suas identidades étnicas, a valorização de suas línguas e ciência.

$\mathrm{O}$ direito a educação indígena passa a ser devidamente contemplada com a promulgação da Lei 10.172/01 que estabelece o Plano Nacional de Educação (PNE). Em seu capítulo 9 trata especificamente sobre a educação indígena. Dando garantias de uma educação plena, com direito a educação escolar nas aldeias ou em classes comuns de escolas próximas, oferecendo atendimento adicional para facilitar sua adaptação e favorecendo a manutenção de sua história, seu modo de vida, sua língua materna e organização sociocultural.

Outras leis foram se seguindo para a afirmação da educação indígena e para o ensino da história e cultura indígena em todas as escolas brasileiras. Entre elas, a lei $\mathrm{n}^{\mathrm{0}} 11.645$, de 10 de março de 2008, que altera a Lei n⿳0 10.639, de 9 de janeiro de 2003, que torna obrigatório o ensino da história e cultura afro-brasileira e indígena em todas as disciplinas escolares, e que serão tratadas a seguir. 


\section{A temática indígena na escola}

Considerando a revisão bibliográfica feita sobre a temática indígena na escola, percebe-se que ao final do século XX e início do século XXI, com a divulgação dos Parâmetros Curriculares Nacionais (1997) a discussão sobre diferenças culturais ganhou mais força na educação brasileira. Até então pouco se discutia sobre pluralidade cultural ou étnica. Tinha-se o conceito de cultura como única, ou seja, algo estruturado e hegemônico.

Ao buscarmos a definição de cultura no dicionário, encontramos esta como o seguinte: "o complexo dos padrões de comportamento, das crenças, das instituições, das manifestações artísticas, intelectuais, etc., transmitidos coletivamente, e típicos de uma sociedade." (FERREIRA, 2008, p. 280)

Como podemos perceber, a definição de cultura vem descrita no plural, ou seja, é um conjunto de fatos e fatores que forma uma cultura.

Tomando por parte que a pluralidade cultural deve fazer parte do currículo escolar, se torna necessário definir como essa temática envolveria todo o currículo. Assim, conforme Moreira e Silva (1994):

A visão tradicional da relação entre cultura e educação/currículo não vê o campo cultural como um terreno contestado. Na concepção crítica, não existe uma cultura da sociedade, unitária, homogênea e universalmente aceita e praticada e, por isso, digna de ser transmitida às futuras gerações através do currículo. Em vez disso, a cultura é vista menos como uma coisa e mais como um campo e terreno de luta. Nesta visão, a cultura é o terreno em que se enfrentam diferentes e conflitantes concepções de vida social, é aquilo pelo qual se luta e não aquilo que recebemos. Assim, nessa perspectiva, a ideia de cultura é inseparável da de grupos e classes sociais (MOREIRA; SILVA, 1994, p. 27).

A reflexão, proposta por Moreira e Silva (1994), elenca a possibilidade da participação direta dos Parâmetros Curriculares Nacionais (PCNs) no currículo escolar.

Desde a publicação dos PCNs em 1997, o ensino brasileiro passou a valorizar a transversalidade de assuntos que anteriormente ficavam restritos a uma área específica de conhecimento - temos como exemplo o estudo das culturas, o qual era desenvolvido no ensino de história apenas, e que ficava reservado ao passado. Em outras palavras, ao se falar em cultura indígena, que é o foco deste trabalho, ela era apresentada como passada e extinta. Com o foco na transversalidade dos conteúdos e com conceito de pluralidade cultural, de acordo com os PCNs, a temática indígena passa a fazer parte do presente, assim, a escola agora deve apresentá-la como uma influência ativa na cultura brasileira. 
Com a ideia da transversalidade, passou-se, então, a discutir em sala de aula alguns assuntos que eram específicos de uma disciplina, em todas as áreas do conhecimento. Conforme os PCNs (1997): “Caberá ao professor mobilizar tais conteúdos em torno de temáticas escolhidas, de forma que as diversas áreas não representem continentes isolados, mas digam respeito aos diversos aspectos que compõem o exercício da cidadania" (BRASIL, 1997, p. 30). Ainda sobre a transversalidade nota-se nos PCNs o (1997): “[...] respeito à possibilidade de se estabelecer, na prática educativa, uma relação entre aprender na realidade e da realidade de conhecimentos teoricamente sistematizados (aprender sobre a realidade) e as questões da vida real (aprender na realidade e da realidade)" (BRASIL, 1997, p.31).

Tendo em vista que, para se trabalhar a cultura na escola precisamos entender que existem diversas culturas que formam as diversas culturas brasileiras, o ensino da história e cultura afro-brasileira e indígena tornou-se lei no Brasil, identificado pelo $\mathrm{n}^{\mathrm{0}} 11.645$, de $10 \mathrm{de}$ março de 2008, que altera o artigo 26-A da Lei no 9.394, de 20 de dezembro de 1996 (BRASIL, 2008), observada a seguir:

\footnotetext{
"Art. 26-A. Nos estabelecimentos de ensino fundamental e de ensino médio, públicos e privados, torna-se obrigatório o estudo da história e cultura afro-brasileira e indígena.

$\S 1$ o O conteúdo programático a que se refere este artigo incluirá diversos aspectos da história e da cultura que caracterizam a formação da população brasileira, a partir desses dois grupos étnicos, tais como o estudo da história da África e dos africanos, a luta dos negros e dos povos indígenas no Brasil, a cultura negra e indígena brasileira e o negro e o índio na formação da sociedade nacional, resgatando as suas contribuições nas áreas social, econômica e política, pertinentes à história do Brasil. $\S 2$ o Os conteúdos referentes à história e cultura afro-brasileira e dos povos indígenas brasileiros serão ministrados no âmbito de todo o currículo escolar, em especial nas áreas de educação artística e de literatura e história brasileiras" (BRASIL, 2008).
}

Conforme a lei, o estudo da história e cultura indígena torna-se obrigatório em todo o ensino fundamental e médio e no currículo de todas as disciplinas, não apenas na História, como era majoritariamente realizado. De acordo com Munduruku (2012):

“[..] É possível hoje verificar a existência não apenas de diversas entidades indígenas especializadas na defesa de temas específicos [...], mas também a aprovação de leis que entendem que as sociedades indígenas estão presentes no contexto nacional para ficar e que, portanto, não se pode mais querer desqualificálas, mas sim aceitá-las como sociedades diferenciadas e que podem contribuir para o processo histórico nacional [...] (MUNDURUKU, 2012. p. 223).

De acordo com Bergamaschi e Gomes (2012): 
Uma prática que vem se afirmando a cada dia nas sociedades indígenas é a educação escolar, instituição imposta pela colonização, tanto no período colonial como a implementada a partir do estado brasileiro [...] iniciativa que visava integrar os povos indígenas à sociedade nacional. No entanto, a escola também foi apropriada por cada grupo de acordo com as suas possibilidades e conveniências [...]. Essa escola indígena que funciona no seio das sociedades ameríndias interage com modos de vida próprios e com a educação da tradição de cada povo. Mas também estão implementados em seu currículo estudos que visam compreender os modos de vida, línguas e ciências não indígenas e assim, apropriados desses conhecimentos, estabelecer um diálogo mais equitativo com essas sociedades. Nos parece que esse é um exemplo bastante concreto de educação intercultural e de relações interculturais, que prevê também aprender na interação com culturas diferentes (BERGAMASCHI, GOMES, 2012, p.54-55).

Se as comunidades indígenas conseguem integrar em seu currículo as outras culturas que estão a sua volta, ou seja, não negam a sua existência, por que as escolas não indígenas têm tanta dificuldade em fazer o mesmo? As autoras ainda complementam justificando que: “[...] a escola terá que fazer um esforço para conhecer esses povos, sua história e sua cultura e, mais especialmente, afirmar uma presença que supera a invisibilidade histórica que se estende até o presente" (BERGAMASCHI, GOMES, 2012).

A escola precisa mostrar ao aluno que a pluralidade cultural existe e está dentro dela, e, com isso, fazer com que os sujeitos desse espaço sintam-se ativos e representados na comunidade em que estão inseridos, ou seja, que o pertencimento àquele lugar seja real.

A partir dessa ideia de pertencimento, para contribuir e facilitar o trabalho do professor, há um esforço do Governo Federal em ampliar o acervo literário das escolas, principalmente do primeiro ciclo de alfabetização, por meio do Pacto Nacional pela Alfabetização na Idade Certa (PNAIC). Este programa, além de promover a formação continuada aos professores alfabetizadores, realiza um investimento bastante grande no acervo literário voltado para a faixa etária de alfabetização. Neste acervo tem-se encontrado um grande número de livros voltados para o ensino da história e cultura afro-brasileira e indígena e que possuem, como sujeitos principais, representantes dos mais diversos grupos étnicos que compõem a nossa nação.

Acreditamos que esse material tem facilitado bastante o trabalho do professor, no que diz respeito ao ensino da pluralidade cultural. Atualmente por meio do acesso a histórias das culturas afro-brasileira e indígena até então pouco representadas nas histórias infantis, os alunos têm podido perceber-se no ambiente da literatura, passando a se sentir elementos chaves de uma história que, até então não pertencia aos que não traziam as características caucasianas. 
Dessa forma, o negro e o indígena surgem como protagonistas ${ }^{4}$, ao lado dos brancos, e essa troca de identidades faz surgir na escola, entre os alunos, uma discussão, ainda que embrionária, de que as diferenças físicas e culturais são vistas, respeitadas e interrelacionadas.

Silva (2013), ao descrever a teoria do currículo, fala que este deve vir embasado nas particularidades de cada indivíduo para, assim, torná-lo protagonista no processo ensino/aprendizagem.

[..] o currículo não é, assim, uma operação meramente cognitiva, em que certos conhecimentos são transmitidos a sujeitos dados e formados de antemão. $\mathrm{O}$ currículo tampouco pode ser entendido como uma operação destinada a extrair, a fazer emergir, uma essência que preexista à linguagem, ao discurso e à cultura. Em vez disso, o currículo pode ser visto como um discurso que, ao corporificar narrativas particulares sobre o indivíduo e a sociedade, constitui-nos como sujeitos - e sujeitos também muito particulares. Pode-se dizer, assim, que o currículo não está envolvido num processo de transmissão ou de revelação, mas um processo de constituição e de posicionamento: de constituição do indivíduo como um sujeito de um determinado tipo e de seu múltiplo posicionamento no interior das diversas divisões sociais(SILVA, 2013, p. 189-190).

Historicamente o currículo escolar se fez a partir de conceitos e ideias únicas, determinando o que seria ou não trabalhado com os alunos, de acordo com a crença de uma cultura homogênea e estática. Currículo este preocupado em ensinar, assim como sugere Silva (2013) coisas e conteúdos desconectados da realidade, tendo os indivíduos como seres passivos.

Contrariando a isso, mais uma vez, Silva (2013), ao defender a teoria do currículo destaca que:

[...] As narrativas contidas no currículo trazem embutidas noções sobre quais grupos sociais podem representar a si e aos outros e quais grupos sociais podem apenas ser representados ou até mesmo serem totalmente excluídos de qualquer representação. Elas, além disso, representam os diferentes grupos sociais de forma diferente: enquanto as formas de vida e a cultura de alguns grupos são valorizadas e instituídas como cânon, as de outros são desvalorizadas e proscritas. Assim, as narrativas do currículo contam histórias que fixam noções particulares sobre gênero, raça, classe noções que acabam também nos fixando em posições muito particulares ao longo desses eixos (SILVA, 2013, p. 190).

Para que a escola consiga afirmar a pluralidade cultural da nossa nação, é importante, então, que as diferenças sejam percebidas e reconhecidas como fatores importantes no

\footnotetext{
${ }^{4}$ Neste texto, a utilização do termo "protagonista" vai ao encontro da utilização feita por SILVA (2000) ao justificar que "[...] dizer "o que somos" significa também dizer "o que não somos". A identidade e a diferença se traduzem, assim, em declarações sobre quem pertence e sobre quem não pertence, sobre quem está incluído e quem está excluído. Afirmar a identidade [e assim o protagonismo] significa demarcar fronteiras, significa fazer distinções entre o que fica dentro e o que fica fora" (SILVA, 2000, p.82).
} 
planejamento curricular de sua instituição. Que o professor se veja como um indivíduo único e cada um de seus alunos também, e que, por isso, são sujeitos importantes e influentes na sociedade. O professor é o grande responsável por rediscutir o currículo.

Trazer essa discussão não é fácil, mas tem se tornado realidade nas escolas. A teoria crítica do currículo, com suas novas indagações, busca ampliar o olhar da escola como transmissora de conhecimentos para um espaço de troca de conhecimentos e de modos de convivências entre as diversas formas de se viver numa sociedade com tantas representações como a nossa. De acordo com Silva (2013):

Fazer perguntas sobre representação é, pois, uma das formas centrais de uma estratégia crítica de análise do currículo. Quais grupos sociais estão representados no conhecimento corporificado do currículo? De que forma eles são descritos? Quais são as idéias de gêneros, de raça, de classe, apresentadas nos diferentes textos curriculares? Quais são os sujeitos da representação contida nos textos curriculares? E quais são objetos? De quais pontos de vista são descritos e representados os diferentes grupos sociais? Quais estratégias são utilizadas para fazer passar as representações como "realidade" ou "verdade" [..] (SILVA, 2013, p. 194-195).

\section{Considerações finais}

Podemos perceber que a temática indígena na escola vem se consolidado aos poucos a partir da criação de leis que determinam o seu ensino e por meio do Movimento Indígena que vem se articulando e buscando uma voz ativa dos povos indígenas do Brasil. As escolas são portadoras de diversas culturas, lembrando aqui a pluralidade cultural característica do Brasil, compreender como a troca de saberes culturais ocorre nas escolas é de extrema importância e nesse contexto, a criação da lei 11.645/08, colabora para que os professores passem a ter um olhar voltado para essa diversidade.

Apesar de ainda ser pouco trabalhada nas escolas, a temática tem aparecido com mais frequência nas disciplinas de Artes, História e Literatura. Muitas vezes em forma de projetos, mas aos poucos ganhando o seu espaço no currículo escolar. Os livros didáticos estão modificando aos poucos a forma de apresentar os povos originários (expressão esta utilizada para se referir aos povos indígenas, pois foram eles que deram origem à nação brasileira, povoando nosso território muito antes da chegada dos europeus.), deixando de mostrá-los apenas no passado e, aos poucos, mostrando os indígenas como pessoas ativas em nossa sociedade e formadoras de nossa história e cultura.

Por fim, trabalhar a temática indígena na escola exige que pessoas pertencentes a esses grupos sejam vistos, que possam atuar ativamente em suas comunidades, sem que uma cultura ou história se sobressaia sobre a outra. Talvez esse seja um dos desafios da lei 11.645/2008, 
potencializar a desacomodação dos conceitos prontos e possibilitar a visualização das diferentes culturas brasileiras na escola.

\section{Referências}

BERGAMASCHI, Maria Aparecida; GOMES, Luana Barth. A temática indígena na escola: ensaios de educação intercultural. In Currículo sem Fronteiras, v.12, n.1, PP. 53-69, Jan./Abr. 2012.

BRASIL. Constituição da República Federativa do Brasil. Brasília: Senado Federal, 1988. Disponível

em: https://www2.senado.leg.br/bdsf/bitstream/handle/id/518231/CF88_Livro_EC91_2016.pdf. Acesso em 12/01/2019.

BRASIL, Documento orientador - PNAIC, 2017. Disponível em: http://pacto.mec.gov.br/images/pdf/doc_orientador_versao_final_20170720.pdf Acesso em: 31/10/2017.

BRASIL. Lei 9.394, de 20 de dezembro de 1996. Estabelece as diretrizes e bases da educação nacional. Disponível em: http://www.planalto.gov.br/ccivil_03/leis/L9394.htm Acesso em 16/07/2018.

BRASIL. Lei $n^{o}$ 10.172, de 9 de janeiro de 2001. Disponível em: http://www.planalto.gov.br/ccivil_03/leis/leis_2001/110172.htm. Acesso em 31/10/2017.

BRASIL. Lei $n^{o}$ 11.645, de 10 de março de 2008. Disponível em: http://www.planalto.gov.br/ccivil_03/_ato2007-2010/2008/lei/111645.htm. Acesso em: 31/10/2017.

BRASIL. Parâmetros Curriculares Nacionais: Apresentação dos temas transversais, Ética. Brasília: MEC/SEF, $1997 . \quad$ Disponível em: http://portal.mec.gov.br/seb/arquivos/pdf/livro081.pdf. Acesso em 31/10/2017.

BRASIL. Parâmetros Curriculares Nacionais: Apresentação dos temas tranversais, Ética. Brasília: MEC/SEF, $1997 . \quad$ Disponível em: http://portal.mec.gov.br/seb/arquivos/pdf/livro081.pdf. Acesso em 31/10/2017.

FERREIRA, Aurélio Buarque de Holanda. Miniaurélio: o minidicionário da língua portuguesa dicionário. $7^{\mathrm{a}}$ ed. Curitiba: Ed. Positivo, 2008.

LIMA, Pablo Luiz de Oliveira; CARIE, Nayara Silva de. Narrativas Maxakali: possibilidades para o ensino de cultura e história indígena. In: Educação em Revista, v.29, n.03, p. 41-62, set. 2013.

MOREIRA, Antônio Flávio; SILVA, Tomaz Tadeu da. Currículo, cultura e sociedade. São Paulo: Cortez, 1994. 
MUNDURUKU, Daniel. O caráter educativo do movimento indígena brasileiro (1970-1990). São Paulo, Paulinas, 2012.

SILVA, Tomaz Tadeu da. (Org.). Alienígenas na sala de Aula: Uma introdução aos estudos culturais em educação. $11^{\text {a }}$ ed. - Petrópolis, RJ: Vozes, 2013.

SILVA, Tomaz Tadeu da. Identidade e diferença: a perspectiva dos estudos culturais I Tomaz Tadeu da Silva (org.), Stuart Hall, Kathryn Woodward. - Petrópolis, RJ: Vozes, 2000.

SOUZA, Maria Izabel Porto de; FLEURI, Reinaldo Matias. Entre limites e limiares deculturas: educação na perspectiva intercultural. In: FLEURI, Reinaldo Matias (org.). Educação intercultural: mediações necessárias. Rio de Janeiro: DP\&A, 2003. p.53-84. 